www.jmscr.igmpublication.org

Impact Factor 5.84

Index Copernicus Value: 71.58

ISSN (e)-2347-176x ISSN (p) 2455-0450

crossref DOI: _https://dx.doi.org/10.18535/jmscr/v5i11.29

Journal Of Medical Science And Clinical Research

\title{
A Study of Surgical Site Infections Following Emergency Non-Traumatic Abdominal Surgeries
}

\author{
Authors \\ Aravind Vimal.S, Ravi Sankar.P, Anvar Ali.A, Badhushah Ibrahim.G.M
}

Department of Surgery, Rajah Muthiah Medical College and Hospital, Chidambaram

\begin{abstract}
Surgical Site Infections (SSIs) outcomes from bacterial contamination for the duration of or after a surgery. A descriptive sort of go sectional examine was carried out in Rajah Muthiah Medical College to have a look at the elements responsible for SSI. One hundred sufferers belonging to distinctive age and both sexes who were admitted for non traumatic emergency abdominal surgery from October 2015 - September 2017, have been blanketed inside this study. Data amassed and analyzed. The incidence of surgical site infections (SSI) turned to be $18 \%$. It turned into cited that age, did no longer motive a statistically great impact on risk of SSI. Among preoperative factors accountable for SSI - threat for SSI is excessive in presence of co morbidities like malnutrition (45.12\%), Diabetis Mellitus (28.5\%), higher degree of wound contamination, delay in surgical operation and longer length of surgical operation. The chance of SSI is increased with the form of surgery - high in colonic surgeries 1 in $2(50 \%)$ and least with obstructed hernia. The presentation of SSI turned into with symptoms like fever, pain, tenderness or wound discharge. The most common organism found to be E.Coli (52.7\%), accompanied by means of staph. Aureus, Klebsiella and pseudomonas. All the organisms were sensitive to imipenem.
\end{abstract}

Keywords: Surgical site infections, host elements, microbial factors, environmental elements, Imipenem.

\section{Introduction}

The term surgical site infection refers to an contamination in the postoperative period, over the incision, deep space or organ accessed at the time of surgery. Surgical site infection (SSI) has continually been a first-rate difficulty of surgery ${ }^{1}$. The hazard of wound infection is prompted however not entirely determined by the degree of infection. Multiple hazard elements and perioperative characteristics can growth the likelihood of surgical site infections. ${ }^{9}$ The threat of contamination is greater in all classes if surgery is taken as an emergency. The incidence of contamination, morbidity and mortality will increase from clean wounds to dirty wounds ${ }^{3}$.
Wound infections typically start among fifth and $10^{\text {th }}$ put up operative day, however they may seen as early as first submit operative day or even years later $^{2}$. Advances in the manipulate of contamination in surgical operation have befell in many methods, such as, aseptic operating theatre strategies have changed poisonous antiseptic techniques, antibiotics have reduced post operative contamination prices, ${ }^{6}$ delayed primary or secondary closure remains beneficial in infected wounds ${ }^{8}$. Despite these measures surgical site contamination causes significant morbidity and excessive fee to the health care system and is becoming increasingly critical in medico-legal factors. 
Criteria for Defining A Surgical Site Infection (SSI)

The term surgical site infection refers to an contamination within the postoperative duration concerning the incision, deep area or organ accessed at the time of surgical procedure.

By the CDC's criterion, SSIs are classified as:

\section{A. Superficial Incisional}

Infection $<30$ days after operation, involving the skin and subcutaneous tissue of incision

\section{B. Deep Incisional}

Infection <30 days of operation if no implant left in place or inside $1 \mathrm{yr}$ if implant is in location.

\section{Organ/Space SSIs}

Infection <30 days after operation entails any a part of the anatomy (e.g. Organs or spaces) aside from the incision, which was opened or manipulated throughout an operation.

\section{Materials and Methods}

This look at was carried out to determine elements responsible for surgical site infections following non-traumatic emergency abdominal operations. 100 sufferers with such operations have been selected, by non-random, purposive sampling from Surgery unit of Rajah Muthiah Medical
College and Hospital at some point of the length of October 2015 to September 2017. All the traumatic cases, clean and dirty wounds had been excluded from the observe. Patients of each sexes and ages were blanketed in the have a look at. All cases have been evaluated clinically. The operative system and associated consistent withoperative elements had been determined at once and recorded. The operational definition for surgical site infection (SSI) was taken as Infections within the vicinity of operational wound within 30 day of operation, showed by microbiological examination. In each cases with discharge from the wound or series of pus anywhere in the area postoperatively, swab taken, cultured for micro organism and sensitivity. Appropriate management given to each of the sufferers of surgical site contamination. Collected facts was analyzed for factors accountable for SSI.

\section{Results}

It determined that age of a hundred sufferers ranged from 40-60 years. The usual surgical site infection rate was $18 \%$. Most of the patients (97 $\%$ ) had been in among 40-60 years (Table 1).

Table 1 - Age Wise Distribution of SSI Age

\begin{tabular}{|l|c|c|c|}
\hline Age & SSI - Present & SSI Absent & Total (100\%) \\
\hline $20-29$ & $2(6.6 \%)$ & $28(93.33 \%)$ & 30 \\
\hline $30-39$ & $4(13.33 \%)$ & $26(86.67 \%)$ & 30 \\
\hline $40 \_49$ & $9(26.47)$ & $25(73.53)$ & 34 \\
\hline $50-59$ & $3(50.00)$ & $3(50.00)$ & 6 \\
\hline TOTAL & $18(18 \%)$ & $82(82 \%)$ & 100 \\
\hline
\end{tabular}

It turned into determined that most of the numerous host elements studied position performed through age of the sufferers have been no longer statistically large ( $\mathrm{p}>0.05$ ).

Out of one hundred operations 55 (55\%) had been for acute appendicitis, 7 (7\%) for ileal perforation,

Table 2 - Incidence of SSI in different abdominal procedures Type of Surgery

\begin{tabular}{|l|c|c|c|}
\hline Surgeries & SSI - Present & SSI - Absent & Total \\
\hline Appendicectomy & $4(7.3 \%)$ & $51(92.7 \%)$ & 55 \\
\hline Repair of ileal perforation / ileostomyand peritoneal toileting & $4(57 \%)$ & $3(43 \%)$ & 7 \\
\hline Repair of duodenal ulcer perforation and thorough peritoneal toileting & $3(16 \%)$ & $15(84.00 \%)$ & 18 \\
\hline Appendicectomy with peritoneal toileting & $5(41.7 \%)$ & $7(58.3 \%)$ & 12 \\
\hline Resection and anastomosis of colon & $2(25 \%)$ & $7(75 \%)$ & 8 \\
\hline TOTAL & $18(18 \%)$ & $82(82 \%)$ & 100 \\
\hline
\end{tabular}


Table 3 - Relation of SSI with Delay to Initiate Surgery

\begin{tabular}{|l|c|c|c|}
\hline Delay to Initiate Surgery (in Hours) & SSI - Present & SSI - Absent & Total \\
\hline$<6$ & - & $5(100 \%)$ & 5 \\
\hline $6-12$ & $2(16.7)$ & $10(83.3)$ & 12 \\
\hline $12-24$ & $3(13.6 \%)$ & $19(86.4 \%)$ & 22 \\
\hline $24-48$ & $4(19 \%)$ & $17(81 \%)$ & 21 \\
\hline $48-72$ & $5(19.35 \%)$ & $25(80.65 \%)$ & 31 \\
\hline$>72$ & $3(33.33 \%)$ & $6(66.66 \%)$ & 9 \\
\hline TOTAL & $18(18 \%)$ & $82(82 \%)$ & 100 \\
\hline
\end{tabular}

Table 4 SSI in Relation to Duration of Surgery

\begin{tabular}{|l|c|c|c|}
\hline Duration of Surgery & SSI - Present & SSI Absent & Total \\
\hline Less than 1 hour & $4(7.7 \%)$ & $48(92.3 \%)$ & 52 \\
\hline $1-2$ hours & $8(21.06 \%)$ & $30(78.94 \%)$ & 38 \\
\hline More than 2 hours & $6(60.00)$ & $4(40.00)$ & 10 \\
\hline TOTAL & $18(18 \%)$ & $82(82 \%)$ & 100 \\
\hline
\end{tabular}

SSI risk increased with degree of wound contamination. The rate of SSI was as high as 14 among contaminated wounds (table 6).

Table 5 - SSI with Wound Contamination

\begin{tabular}{|l|c|c|c|}
\hline Type of Wound & SSI - Present & SSI - Absent & Total \\
\hline Clean contaminated & $4(7.3 \%)$ & $51(92.7 \%)$ & 38 \\
\hline Contaminated & $14(31.1 \%)$ & $31(68.9 \%)$ & 11 \\
\hline TOTAL & $18(18 \%)$ & $82(82 \%)$ & 100 \\
\hline
\end{tabular}

Among 100 patients, 19 developed some type of discharge from the wounds/ collection of pus in the abdominal area. Commonest was (10cases) muddy odorless pus, followed by thick creamy pus, bluish green pus, yellow fishy odoured pus and serosanguinous discharge (TABLE 6).

Table 6 - Type of Discharge and Organism Isolated

\begin{tabular}{|l|c|c|}
\hline Character of Discharge & Frequency-No. of Cases & Organism Isolated \\
\hline Thin muddy odourless & $10(52.70 \%)$ & Escherechia Coli \\
\hline Thick creamy & $4(21 \%)$ & Staphylococcus Aureus \\
\hline Yellow fishy odour & $2(10 \%)$ & Klebsiella Pneumoniae \\
\hline Blue green & $2(10 \%)$ & Pseudomonas Aeruginosa \\
\hline serosanguinous & 1 & No growth \\
\hline \multicolumn{2}{|c|}{ TOTAL } & 19 \\
\hline
\end{tabular}

On microbiological evaluation of submit operative wound discharge, the incriminated organisms have been stated as 10, $(52.70 \%)$ Escherischia Coli, at the same time as $4(21 \%)$ infections have been because of Staph. Aureus and (10\%) each for Klebsiella Pneumonae and Pseudomonus Aeruginosa (table 6).

The sensitivity sample of organisms to antibiotics were studied. All $(100 \%)$ the organisms isolated were sensitive to Imipenem, linezolid shows $60 \%$ sensitivity.

\section{Discussion}

Surgical Site Infections (SSIs), formerly referred to as post operative wound infections, end result from bacterial infection at some point of or after a surgical operation. The danger of contamination is more in all classes if surgical operation is achieved as an emergency. Surgical site infection reasons great morbidity, mortality and excessive value to the health care system and is becoming an increasingly number of essential in medicolegal aspects. $^{5}$ 
In this examine it have been tried to find out the common organisms responsible for surgical site infections following emergency nontraumatic abdominal operations. In addition, the sensitivity of the microorganisms were ascertained. Further, factors responsible for infection were decided, with the intention to be helpful to prevent infection in destiny during the similar kinds of surgical operation.

However, 100 cases having emergency nontraumatic abdominal operations were decided on purposively. Patients with trauma, clean and dirty wounds were excluded from the examine. Out of one hundred abdomen operations it turned into found out that, overall surgical site infection rate become $18 \%$. It become observed that some of the various host elements like age and sex of the patients have been not shown statistically big difference, however presence of comorbidity played a considerable role in causing SSI. ${ }^{4}$ Among the perioperative/environmental elements category of operations, kinds of incisions, sterilization of instruments, theatre environment, but length of operation and degree of wound infection played statistically big position. In recognize of put up operative wound discharge and incriminated organisms it was located that maximum of the SSIs $10(52.7 \%)$ were due to Escherischia Coli, while $4(21 \%)$ infections had been because of Staph. Aureus and 2 (10\%) had been because of Klebsiella Pneumonae and Pseudomonus Aeruginosa.

It was found out that a couple of host factors (e.g. Presence of co-morbidity consisting of diabetes, malnutrition, obesity and so on.), environmental elements (e.g. Length of exposure of the injuries to the surroundings and degree of wound contamination) and various micro-organisms (including E. Coli, S. Aureus, Klebsiella and pseudomonus) had been responsible for surgical site infections. So, to save patients from SSI emphasis have to be received for all of the vital factors chargeable for infection. ${ }^{7}$

\section{Conclusion}

This examine, conducted in Department of surgical treatment Rajah Muthaih Medical College Hospital, Chidambaram, during the duration from October, 2015 to September, 2017. It may be concluded from the findings of the examine that microorganisms which can be everyday inhabitants of our body are specially account for surgical site infection (SSI). Various host factors like malnutrition, obesity, sufferers information approximately hygiene, presence of co-morbidity etc. Coupled with environmental factors together with condition of the wounds, postpone to initiate operation, period of operation, extended exposure of peritoneal cavity to environment, prophylactic use of antibiotics and elements associated with surgical procedure like incision, sort of operation greatly make contributions to occurrences of SSI. So, satisfactory of surgical care which include instantaneous evaluation of sufferers, resuscitative measures, good enough preparation of patients and aseptic surroundings are essential for manage of SSI. Moreover in absence of surprisingly superior surgical services, preoperative resuscitative devices, cutting-edge operation theatre centers and sophisticated sterilization technique it's far essential to use prophylactic antibiotics to encounter the numerous types of micro-organisms liable for surgical site infection, specifically E. Coli and Staph. Aureus.

\section{References}

1. Williams, N.S., Bulstrode, C.J.K., O'conel, P.R., 2008. Bailey and Love's Short Practice of Surgery, 25 th ed. 338 Euston Road, London NW1 3BH: Hodder Arnold, 32-48.

2. Doharty, G. M., Way L.W., 2006. Current Surgical Diagnosis, 12th ed. McGraw Hill, USA; p. 106-107.

3. Kirk R.M., Ribbans, W.J., 2004. Clinical surgery in general (RCS course manual), 4th ed. Churchill livingstone, London, UK; 206-382. 


\section{JMSCR Vol||05||Issue||11||Page 29983-29987||November}

4. Nichols R.L., 2009. Preventing Surgical Site Infections: A Surgeon's Perspective, Centre for Disease Control; Vol. 7, 1-10.

5. Razavi, S. M., Ibrahimpoor, M., Sabouri, A., Kashani, Jafarian A, 2005. Abominal surgical site infections: incidence and risk factors at an Iranian teaching hospital, BMC surgery, 5(2), 3-5.

6. The Medical Letter. 2001. Antimicrobial prophylaxis in surgery.

7. The Medical Letter 43: 1116-1117.Cruse, P.J.E., Frood, R., 1980. The epidemiology of wound infection. Surgical clinics of North America, 60 (1), 27-40.

8. Surgical Site Infection Survillance for general surgery, 2009. Wexford General Hospital Surgical Site Infection (SSI) data report, [online].

9. Sultan, J., Bilal, H. B., Kiran, H., Bilal, B. B., Yusuf, A., 2007. Emergency Abdominal Surgery; incidence of intra abdominal sepsis and its management, Professional Med J,14(1), 10-16. 